\title{
Message from the Former Editor-in-Chief, Dr. Sergio La Porta
}

It has been an honor for me to serve as the Editor-in-Chief of the JSAS from 2011-2019, and I would like to thank all those without whom it would not have been possible to produce the journal. In particular, I would like to thank the contributors, reviewers, and readers with whom I have worked. I would also like to thank Prof. Barlow Der Mugrdechian for all his help with the lay-out, his support, and advice. I would also like to thank the Editorial Advisory Committees and Boards of Academic Advisors with whom I have collaborated, as well as both past and present Executive Committees of the SAS who placed their confidence in me. Finally, I would like to express my gratitude to the Dolores Zohrab Liebmann Fund, which has generously supported the JSAS over the years. Thanks in large part to the diligence of sas President, Dr. Bedross Der Matossian, our efforts with BRILL succeeded and the JSAS begins a new era in its history. I was also extremely pleased in the decision of the sAs Executive Committee to appoint Dr. Tamar Boyadjian as the new editor of the Journal. Dr. Boyadjian brings the enthusiasm, scholarly acumen, and fresh perspectives that the editing of the journal requires. I'm confident that the JSAS will achieve significant milestones under her guidance. This issue truly marks an exciting new beginning for the Journal and for Armenian Studies in general.

Since the last issue of JSAS appeared, we have lost two valuable scholars of Armenian Studies and personal friends, Professors Robert Hewsen and Robert Thomson. The immense scholarly contributions of both are well known, but I feel fortunate to be among those who also had the opportunity to know them personally. Both men were intellectually inspiring and represented what was best about academia. Their presence is deeply missed.

When I started Armenian Studies some two and a half decades ago, it was a bit of a lonely field, especially for a younger person. It has been invigorating to see how interest in Armenian Studies and the number of students of Armenian Studies has markedly increased since then. I hope, encourage, and expect that many of these younger scholars will be contributing to the pages of the JSAS in its new incarnation. Nevertheless, the academic environment today remains a challenging one, and these scholars will need our support. I would 
like to end this brief note with an appeal to our readers to provide our new generation of Armenian Studies scholars as much support and encouragement as possible. Thank you and please join me in celebrating the future of JSAS and of Armenian Studies.

\section{Sergio La Porta}

